\title{
Efficacy of late postnatal dexamethasone on weaning from invasive mechanical ventilation in extreme premature infants
}

\author{
Waleed Kurtom ${ }^{1}$ - Augusto Schmidt ${ }^{2}$ Deepak Jain ${ }^{3}$ Silvia Vanbuskirk ${ }^{2} \cdot$ Alini Schott $^{2} \cdot$ Eduardo Bancalari $^{2}$. \\ Nelson Claure $\mathbb{B}^{2}$
}

Received: 1 June 2020 / Revised: 16 March 2021 / Accepted: 18 May 2021 / Published online: 28 May 2021

(c) The Author(s), under exclusive licence to Springer Nature America, Inc. 2021

\begin{abstract}
Objective To evaluate the short-term respiratory effects of PND in a cohort of ventilator-dependent premature infants. Study design Clinical data from 106 infants 23-28 weeks gestation who received PND for weaning from MV during 2011-2017 were evaluated. PND was started at a dose of $0.1 \mathrm{mg} / \mathrm{kg} / \mathrm{d}$ tapered over 5-7 d. Treatment success was defined as extubated and free from MV on d14 after start of treatment.

Result Treatment was successful in $83(78 \%)$ infants. Demographics and age of treatment did not differ between groups. In the failure group, a higher proportion were on $\mathrm{HFOV}$ and $\mathrm{FiO}_{2} \geq 0.50$ before treatment, compared to the successful group.

Conclusion In most infants, PND resulted in successful weaning from MV. Reduced need for oxygen in infants not extubated may be beneficial, but it is unknown if this offsets the risks. The long-term effects PND in ventilator dependent infants need to be evaluated.
\end{abstract}

\section{Introduction}

Abnormal lung development and bronchopulmonary dysplasia (BPD) in preterm infants are in part due to ventilator-induced lung injury and are associated with prolonged mechanical ventilation [1-3]. The use of postnatal steroids in these infants is associated with improved lung function and faster weaning from respiratory support [4-8]. However, use of post-natal dexamethasone (PND) has been associated with increased risk of neurodevelopmental impairment [4, 9]. Most of these trials started PND at an early chronological age

Nelson Claure

nclaure@miami.edu

1 Division of Neonatology, Department of Pediatrics, Children's National Medical Center, Washington, DC, USA

2 Department of Pediatrics, Division of Neonatology, University of Miami School of Medicine, Miami, FL, USA

3 Department of Pediatrics, Division of Neonatology, Rutgers University, Robert Wood Johnson Medical School, New Brunswick, NJ, USA
( $<7$ days) and received higher doses of the drug for a prolonged period of time. Trials using late PND ( $>7$ days) also showed respiratory benefits without increased neurological impairment but were not powered for this outcome $[4,10,11]$.

These findings led to a more measured approach to postnatal corticosteroids, optimizing the benefits of PND by targeting the infants at highest risk of long-term respiratory morbidity and using lower doses and later administration in hopes of minimizing side effects [4-7, 9, 12-14]. However, the effectiveness of these strategies has not been adequately tested in randomized trials. The only trial to test such strategy was terminated early due to loss of physician equipoise in the wake of concerns regarding worse neurodevelopmental outcomes with PND [11]. Recently, smaller and sicker extremely premature infants survive with increasing frequency and require mechanical ventilation for longer periods of time. These infants receive PND later in their hospital course but the effect of this approach on weaning ventilation and oxygen support has not been fully evaluated. The objective of this study was to evaluate the short-term effects of a short course of PND on the ensuing respiratory trajectory in a cohort of ventilator-dependent extreme premature infants. Secondarily, to identify factors associated with the response to PND. 


\section{Methods}

Data from a cohort of ventilator dependent preterm infants 23-28 weeks gestational age (GA) admitted to the newborn intensive care unit (NICU) at Holtz Children's Hospital, Jackson Memorial/University of Miami Medical Center during 2011-2017 and who received PND for weaning from invasive mechanical ventilation were analyzed. Infants were excluded if their course of PND was given after 36 weeks corrected GA. Data from this cohort were part of the clinical data collected prospectively from all NICU admissions into the Neonatal-Perinatal database of the Division of Neonatology under approval of the University of Miami Institutional Review Board and the Jackson Health System Clinical Research Office. Analysis included data on the following prenatal and postnatal variables: GA, race, gender, clinical chorioamnionitis, preeclampsia (defined as new onset hypertension after the 20th week of pregnancy accompanied with new onset proteinuria, thrombocytopenia, impaired liver function, impaired renal function, pulmonary edema, or cerebral or visual disturbances), maternal chronic hypertension (defined as hypertension predating conception or prior to 20 weeks of gestation), antenatal steroids (ANS, complete course), small for gestational age (SGA, defined as birth weight $<10$ th percentile), sepsis (positive blood culture), echo confirmed patent ductus arteriosus, severe respiratory distress syndrome (RDS, defined as administration of a fraction of inspired oxygen $\left(\mathrm{FiO}_{2}\right) \geq 0.30$ for $\geq 12 \mathrm{~h}$ on postnatal day 1 ), duration of invasive mechanical ventilation (MV, days) and age at last use of invasive mechanical ventilation (days). The decision to extubate each individual patient and re-intubate if necessary were at the discretion of the clinical team. In general, the indications for extubation included blood gases within acceptable limits and low ventilator parameters in combination with arterial oxygen saturation within the 90-95\% range while on $\mathrm{FiO}_{2}$ below 0.4. All infants received a loading dose of caffeine the day before extubation and a daily maintenance dose thereafter. After extubation, they were placed on nasal CPAP or NIMV with settings at the discretion of the clinical attending team.

PND was defined by the administration of dexamethasone with the intention of improving lung function and weaning from invasive MV. In general, infants received an intravenous dexamethasone dose starting at $0.1 \mathrm{mg} / \mathrm{kg} /$ day and tapered over 5-7 days. The length and treatment regimen were at the discretion of the attending neonatologists based on the clinical condition of the patient. Treatment success was defined as free from MV by day 14 from the initiation of PND. Treatment failure was defined as extubation with subsequent reintubation within 14 days of PND initiation or remaining on MV (not extubated) by d14 after starting PND.

Descriptive statistics (mean, standard deviation, and frequency) were calculated for each of the outcome groups.
Characteristics of neonates with treatment success were compared to those who did not reach success, using binomial testing for categorical variables by Chi-Square, $\mathrm{T}$ Test for continuous variables or the nonparametric Mann-Whitney U Test when the Levene statistic test showed the groups did not have equal variances. General Linear Model for Repeated Measures was used to compare differences in $\mathrm{FiO}_{2}$ and changes $\mathrm{FiO}_{2}$ from baseline between success and failure groups. Multivariate stepwise binary logistic regression analysis (LRA) was used to model the association between demographic, perinatal and respiratory support parameters prior to the start of PND with successful weaning from mechanical ventilation by day 14 . Other factors evaluated in the model included gestational age, age at start of PND, race, gender, maternal preeclampsia, chorioamnionitis, small for gestational age, multiple pregnancy, Apgar score $<5$ at $5 \mathrm{~min}$, severe respiratory distress syndrome, on mechanical ventilation during first day after birth, history of patent ductus arteriosus and sepsis. $P$ values $<$ 0.05 were considered statistically significant. Data were analyzed using IBM SPSS Statistics (version 26).

\section{Results}

During years 2011-2017, there were 915 infants of 23-28 weeks gestation admitted to the NICU at this center and 755 of these infants received invasive mechanical ventilation. The cohort in this study included 106 ventilator dependent premature infants who received PND for weaning from invasive mechanical ventilation.

In 83 of the 106 infants (78\%) PND treatment was successful. Eighty percent of the infants in the successfully treated group were extubated shortly after PND administration (Fig. 1).

The PND treatment success and failure groups did not differ in regard to GA, BW and other demographics

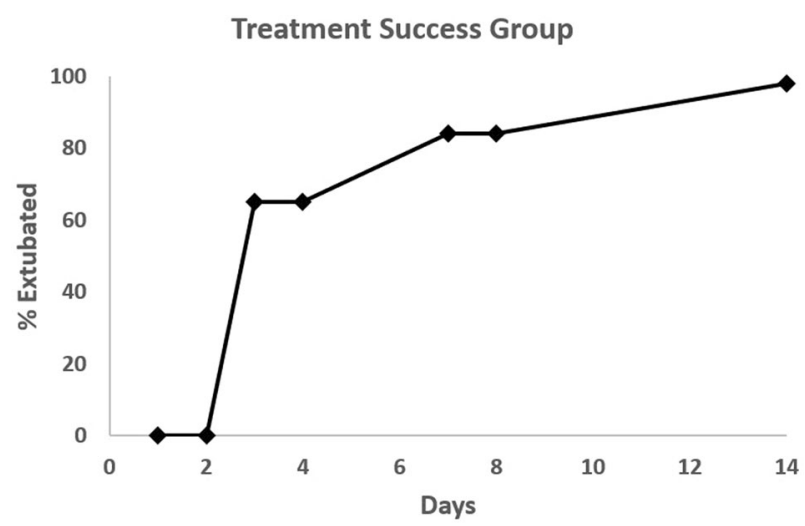

Fig. 1 Days to extubation from start of PND. Most infants that were successfully extubated by day 3 after the start of PND (65\%). 
Table 1 Demographics, prenatal, and postnatal characteristics.

\begin{tabular}{lcc}
\hline Characteristic & $\begin{array}{l}\text { Treatment Success } \\
(n=83)\end{array}$ & $\begin{array}{l}\text { Treatment Failure } \\
(n=23)\end{array}$ \\
\hline Gestational age (weeks) & $25.6 \pm 1.6$ & $25.5 \pm 1.9$ \\
Birth weight (g) & $676 \pm 145$ & $662 \pm 292$ \\
Small for gestational age & $17(21)$ & $8(35)$ \\
Apgar score <5 at 5 min & $14(17)$ & $4(17)$ \\
Multiple pregnancy & $19(23)$ & $4(17)$ \\
Female & $48(58)$ & $11(48)$ \\
Black & $45(54)$ & $11(48)$ \\
Chronic maternal & $22(27)$ & $5(22)$ \\
hypertension & & $10(44)$ \\
Sepsis & $38(46)$ & $4(17)$ \\
Clinical chorioamnionitis & $10(12)$ & $7(30)$ \\
Preeclampsia & $23(28)$ & $22(96)$ \\
Antenatal steroids & $76(92)$ & $20(87)$ \\
PDA & $77(93)$ & $19(83)$ \\
Surfactant treatment & $75(90)$ & $10(44)$ \\
Severe RDS & $25(30)$ & \\
\hline Data &
\end{tabular}

Data are mean \pm SD or number $(\%)$

$P D A$ patent ductus arteriosus, $R D S$ respiratory distress syndrome

(Table 1). PND was started at approximately similar postnatal age ( $\sim 55$ days) and postmenstrual age (PMA, $\sim 33$ weeks) in both groups. At the time of initiating PND, infants that failed treatment were more likely to be on HFOV and receiving $\mathrm{FiO}_{2}>0.5$, which suggests a more severe respiratory illness because HFOV in this center is used as a rescue therapy for sicker infants for whom conventional IPPV is not sufficient. (Table 2). Infants failing treatment spent more time on high frequency oscillatory ventilation (HFOV) and MV before and after PND and received more courses and doses of PND (Table 2).

LRA demonstrated that the type of mechanical ventilatory support (HFOV) and particularly oxygen requirement with $\mathrm{FiO}_{2}>0.50$ at the start of PND treatment were significantly associated with reduced odds for successful weaning (Table 3).

The administered $\mathrm{FiO}_{2}$ was lower at the time PND was started and remained lower until d14 in the group of infants that were successfully extubated compared to the treatment failure group ( $p=0.01$ by GLMRM) who failed. (Fig. 2). In contrast, the decrease in $\mathrm{FiO}_{2}$ at days 3, 7, and 14 from the start of PND was larger in the treatment failure group $(p=0.002$ by GLMRM, Fig. 3$)$.

\section{Discussion}

There is limited information on the respiratory parameters associated with extubation success in extremely premature infants who receive PND later in their hospital course.
Table 2 Clinical characteristics at the time of treatment and outcomes.

\begin{tabular}{lll}
\hline Characteristic & $\begin{array}{l}\text { Treatment } \\
\text { success }(n= \\
83)\end{array}$ & $\begin{array}{l}\text { Treatment } \\
\text { failure }(n=23)\end{array}$ \\
\hline $\begin{array}{l}\text { Age at start of PND course (days) } \\
\text { PMA at start of PND course }\end{array}$ & $\begin{array}{l}53 \pm 54 \\
\text { (weeks) }\end{array}$ & $56 \pm 77$ \\
PND course \# of doses & $10 \pm 6$ & $15 \pm 14^{*}$ \\
PND course \# of days & $5 \pm 3$ & $8 \pm 7^{*}$ \\
$\begin{array}{l}\text { On HFOV at start of PND } \\
\text { On IPPV at start of PND }\end{array}$ & $14(17)$ & $10(44)^{*}$ \\
On FiO $2>0.5$ at start of PND & $31(37)$ & $13(57)^{*}$ \\
Hospital stay (days) & $158 \pm 66$ & $200 \pm 64$ \\
$\begin{array}{l}\text { Duration of invasive mechanical } \\
\text { ventilation (days) }\end{array}$ & $45(30-61)$ & $92(40-144)^{* *}$ \\
Age at last use of invasive & $50(33-68)$ & $77(54-101)^{* *}$ \\
mechanical ventilation (days) & & $24(9-40)$ \\
$\begin{array}{l}\text { Duration of HFOV (days) } \\
\text { Duration of oxygen }\end{array}$ & $10(0-21)$ & $186 \pm 66^{*}$ \\
supplementation (days) & $128 \pm 71$ & \\
\hline
\end{tabular}

Data are mean $\pm \mathrm{SD}$, median (interquartile range) or number $(\%)$.

$P N D$ post-natal dexamethasone, PMA post-menstrual age, HFOV high-frequency oscillatory ventilation, IPPV intermittent positive pressure ventilation

${ }^{*} p<0.05$ by T-Test, ${ }^{* *} p<0.05$ by Mann-Whitney U Test

Table 3 Factors associated with weaning from mechanical ventilation after a course of dexamethasone.

\begin{tabular}{ll}
\hline Factor & Odds ratio $(95 \% \mathrm{CI})$ \\
\hline IPPV and $\mathrm{FiO}_{2} \geq 0.50$ at start of PND* & $0.255(0.074-0.875)$ \\
HFOV and $\mathrm{FiO}_{2}<0.50$ at start of $\mathrm{PND}^{*}$ & $0.153(0.020-1.145)$ \\
HFOV and $\mathrm{FiO}_{2} \geq 0.50$ at start of $\mathrm{PND}^{*}$ & $0.140(0.038-0.512)$ \\
\hline
\end{tabular}

By multivariable stepwise binary logistic regression analysis. Other variables evaluated in the model included gestational age, age at start of PND, race, gender, maternal preeclampsia, chorioamnionitis, small for gestational age, multiple pregnancy, Apgar score $<5$ at $5 \mathrm{~min}$, severe respiratory distress syndrome, on mechanical ventilation during first day after birth, history of patent ductus arteriosus and sepsis.

$C I$ confidence interval, $P N D$ post-natal dexamethasone, HFOV highfrequency oscillatory ventilation, IPPV intermittent positive pressure ventilation

*Referenced to IPPV and $\mathrm{FiO}_{2}<.50$ at start of PND

The present data shows an association between late PND administration at a mean age of 8 weeks and successful extubation in infants that are chronically ventilator dependent.

These findings are in agreement with previous studies showing a temporal association between earlier dexamethasone administration and extubation in the first month after birth [15-17]. A retrospective study that included 74 preterm infants that received dexamethasone for 24 days 


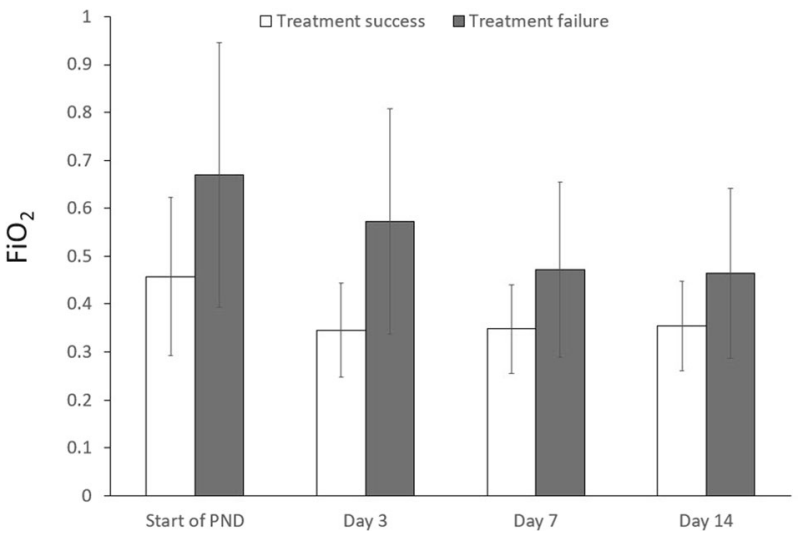

Fig. $2 \mathrm{FiO}_{2}$ requirement from start to $\mathbf{d 1 4}$ of PND. PND was associated with a decrease in $\mathrm{FiO}_{2}$ in both groups of infants. Infants who were successfully extubated received consistently lower $\mathrm{FiO}_{2}$ from the start of PND until day 14 compared to the infants who failed. ( $p=0.001$ by Generalized Linear Model for Repeated Measures, data are mean $\pm \mathrm{SD}$ )

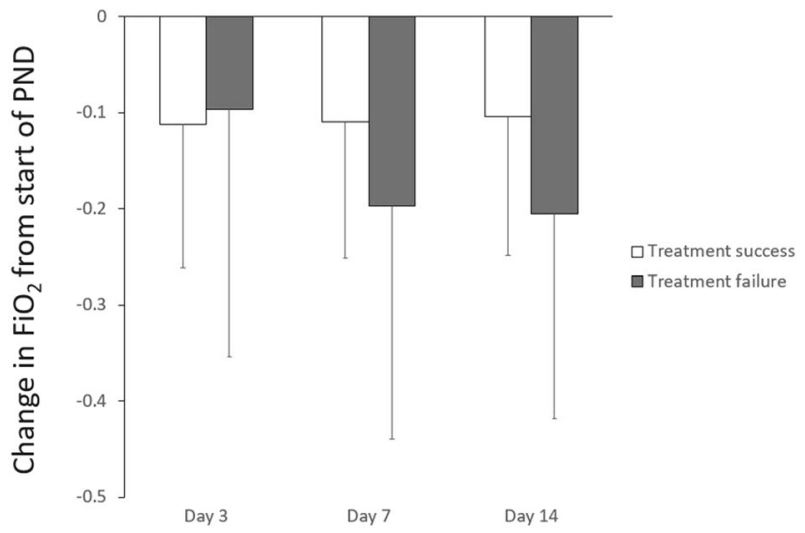

Fig. 3 Change $\mathrm{FiO}_{2}$ requirement from start of PND to days 3, 7, and 14. Although PND was associated with a decrease in $\mathrm{FiO}_{2}$ in both groups of infants, infants who were not successfully extubated had a greater decrease in $\mathrm{FiO}_{2}$ from the start of PND during days 3, 7 , and 14 compared to the successfully weaned infants. ( $p=0.002$ by Generalized Linear Model for Repeated Measures, data are mean $\pm \mathrm{SD}$ )

showed that the median time to extubation was 6 days and that the strongest predictive factors for successful extubation were larger gestational age and PMA [16]. The findings of this study also coincide with a recent report by Nath et al. [17] describing the use of PND at a slightly earlier mean postnatal age that resulted in 59\% success of extubation by day 7 after treatment and a considerable reduction in respiratory support.

Other studies have shown that about three out of four infants that receive dexamethasone for a mean duration of 1 week were extubated, but information about the factors associated with success are lacking $[18,19]$. In the present study, requiring $\mathrm{HFOV}$ and higher $\mathrm{FiO}_{2}$ at the start of PND were identified as risk factors for treatment failure.
Although the need for higher $\mathrm{FiO}_{2}$ as a factor associated with PND failure for weaning from invasive mechanical ventilation can be generalized, the failure group had a greater reduction in $\mathrm{FiO}_{2}$. Requiring $\mathrm{HFOV}$ was also identified as a factor associated with treatment failure but it should be noted that HFOV is used in this center as a rescue therapy when conventional IPPV fails and therefore this observation may not apply to centers where the approach to the use high frequency ventilation is different. Regardless of the extubation success or failure, or lack of extubation, the requirement for supplemental oxygen was consistently reduced following PND in this cohort. Given the wellestablished detrimental effects of supplemental oxygen on the lung, this improvement in oxygenation raises the question as to whether PND administration should be considered for reducing oxygen supplementation. However, the potential benefits of a lower oxygen exposure must outweigh any risk of detrimental neurologic effects before this can be recommended.

One study comparing two cohorts in 1995 and 2006 for babies born before 26 weeks' gestation showed that the later cohort received shorter courses and lower doses of PND with no major differences in the proportions of babies surviving with BPD. There was, however, a slight increase in supplemental oxygen at discharge in the later cohort [20]. In this study we opted for not evaluating the effect of PND on BPD incidence or severity because the age of BPD assessment overlapped with the start of PND in many of the infants in the cohort. Nonetheless, the total duration of mechanical ventilation and oxygen supplementation were significantly lower in the treatment success group. This however may be in large part related to the fact that infants in these groups had a milder lung disease at the start of PND treatment.

There are limitations and strengths in the present study. These are primarily related to the nature of retrospective analysis of clinical data where indication biases may affect the outcomes. Specifically, the decision to extubate, mode of non-invasive respiratory support (CPAP or NIMV) as well as indications to re-intubate were all at the discretion of the clinical attending team. Although factors such as GA, BW, age at PND treatment, and other demographics did not differ between the treatment failure and success groups, the two groups were clearly different in regard to their lung function at the start of treatment. This may have influenced the clinician's decision to attempt extubation and thereby predetermined the failure, as defined in this study. Data in this study were collected from a large single center with similar clinical practices. In contrast, reports on the effects and associations between PND usage and short- and longterm respiratory outcomes are meta-analyses or large pooled reviews that require considerable statistical adjustment for confounding factors. 
Different dosing regimens and time points for treatment may potentiate the efficacy of PND on respiratory outcomes and should be further evaluated [21, 22]. Although not generalizable, the use of PND in older extreme preterm infants to facilitate extubation or reduce oxygen supplementation are supported by the results of this study.

This study showed that PND administration after approximately 8 weeks of age was associated with successful extubation in a large proportion of treated infants. The fact that treatment failure was associated with higher levels of ventilatory support and oxygen requirements at the start of dexamethasone treatment may facilitate patient selection for treatment. It can be argued that the decrease in supplemental oxygen in the failure group could possibly be considered a treatment success, but this potential benefit should be contrasted to the long-term risks associated with PND. Before the findings of this study can be translated into a recommendation, the risks of these treatment strategy need to be carefully evaluated.

Acknowledgements The study received unrestricted support from the University of Miami Project NewBorn, a philanthropic organization that did not participate in any aspect of the research.

\section{Compliance with ethical standards}

Conflict of interest The authors declare no competing interests.

Publisher's note Springer Nature remains neutral with regard to jurisdictional claims in published maps and institutional affiliations.

\section{References}

1. Bancalari E, Abdenour GE, Feller R, Gannon J. Bronchopulmonary dysplasia: clinical presentation. J Pediatr. 1979;95: 819-23. (5 Pt 2)

2. Northway WH Jr., Moss RB, Carlisle KB, Parker BR, Popp RL, Pitlick PT, et al. Late pulmonary sequelae of bronchopulmonary dysplasia. N Engl J Med. 1990;323:1793-9.

3. Taghizadeh A, Reynolds EO. Pathogenesis of bronchopulmonary dysplasia following hyaline membrane disease. Am J Pathol. 1976;82:241-64.

4. Doyle LW, Cheong JL, Ehrenkranz RA, Halliday HL. Late (>7 days) systemic postnatal corticosteroids for prevention of bronchopulmonary dysplasia in preterm infants. Cochrane Database Syst Rev. 2017;10:CD001145.

5. Avery GB, Fletcher AB, Kaplan M, Brudno DS. Controlled trial of dexamethasone in respirator-dependent infants with bronchopulmonary dysplasia. Pediatrics. 1985;75:106-11.

6. Bergenfeldt M, Axelsson L, Ohlsson K. Release of neutrophil proteinase 4(3) and leukocyte elastase during phagocytosis and their interaction with proteinase inhibitors. Scand J Clin Lab Invest. 1992:52:823-9.
7. Couser JI Jr., Berley J, Timm EG. Intrapleural urokinase for loculated effusion. Chest. 1992;101:1467-9.

8. Doyle LW, Cheong JL, Ehrenkranz RA, Halliday HL. Early ( $<8$ days) systemic postnatal corticosteroids for prevention of bronchopulmonary dysplasia in preterm infants. Cochrane Database Syst Rev. 2017;10:CD001146.

9. Yeh TF, Lin YJ, Lin HC, Huang CC, Hsieh WS, Lin CH, et al. Outcomes at school age after postnatal dexamethasone therapy for lung disease of prematurity. N Engl J Med. 2004;350:1304-13.

10. Doyle LW, Davis PG, Morley CJ, McPhee A, Carlin JB, Investigators DS. Outcome at 2 years of age of infants from the DART study: a multicenter, international, randomized, controlled trial of low-dose dexamethasone. Pediatrics. 2007;119:716-21.

11. Doyle LW, Davis PG, Morley CJ, McPhee A, Carlin JB, Investigators DS. Low-dose dexamethasone facilitates extubation among chronically ventilator-dependent infants: a multicenter, international, randomized, controlled trial. Pediatrics. 2006;117:75-83.

12. Doyle LW, Halliday HL, Ehrenkranz RA, Davis PG, Sinclair JC. Impact of postnatal systemic corticosteroids on mortality and cerebral palsy in preterm infants: effect modification by risk for chronic lung disease. Pediatrics. 2005;115:655-61.

13. Zeng L, Tian J, Song F, Li W, Jiang L, Gui G, et al. Corticosteroids for the prevention of bronchopulmonary dysplasia in preterm infants: a network meta-analysis. Arch Dis Child Fetal Neonatal Ed. 2018;103:F506-F11.

14. Doyle LW, Halliday HL, Ehrenkranz RA, Davis PG, Sinclair JC. An update on the impact of postnatal systemic corticosteroids on mortality and cerebral palsy in preterm infants: effect modification by risk of bronchopulmonary dysplasia. $\mathrm{J}$ Pediatr. 2014;165:1258-60.

15. Yates HL, Newell SJ. Minidex: very low dose dexamethasone $(0.05 \mathrm{mg} / \mathrm{kg} /$ day $)$ in chronic lung disease. Arch Dis Child Fetal Neonatal Ed. 2011;96:F190-4.

16. Kuschel C, Evans N, Lam A. Prediction of individual response to postnatal dexamethasone in ventilator dependent preterm infants. Arch Dis Child Fetal Neonatal Ed. 1998;78:F199-203.

17. Nath S, Reynolds AM, Lakshminrusimha S, Ma C, Hudak ML, Ryan RM. Retrospective analysis of short-term respiratory outcomes of three different steroids used in clinical practice in intubated preterm infants. Am J Perinatol. 2019. Epub 2019/08/06. https://doi.org/ 10.1055/s-0039-1694004. PubMed PMID: 31382299.

18. Tanney K, Davis J, Halliday HL, Sweet DG. Extremely low-dose dexamethasone to facilitate extubation in mechanically ventilated preterm babies. Neonatology. 2011;100:285-9.

19. Cuna A, Govindarajan S, Oschman A, Dai H, Brophy K, Norberg $\mathrm{M}$, et al. A comparison of 7-day versus 10-day course of low-dose dexamethasone for chronically ventilated preterm infants. J Perinatol. 2017;37:301-5.

20. Costeloe KL, Hennessy EM, Haider S, Stacey F, Marlow N, Draper ES. Short term outcomes after extreme preterm birth in England: comparison of two birth cohorts in 1995 and 2006 (the EPICure studies). BMJ. 2012;345:e7976.

21. Onland W, Offringa M, De Jaegere AP, van Kaam AH. Finding the optimal postnatal dexamethasone regimen for preterm infants at risk of bronchopulmonary dysplasia: a systematic review of placebo-controlled trials. Pediatrics. 2009;123:367-77.

22. Harmon HM, Jensen EA, Tan S, Chaudhary AS, Slaughter JL, Bell EF, et al. Timing of postnatal steroids for bronchopulmonary dysplasia: association with pulmonary and neurodevelopmental outcomes. J Perinatol. 2020;40:616-27. 